\title{
The Medullary Pacemaker Nucleus Is Unnecessary for Electroreceptor Tuning Plasticity in Sternopygus
}

\author{
Michael B. Ferrari and Harold H. Zakon \\ Department of Zoology, University of Texas, Austin, Texas 78712
}

\begin{abstract}
Tuberous electroreceptors of the weakly electric fish Sternopygus macrurus are closely tuned to the frequency of electric organ discharge (EOD), which is determined by a medullary pacemaker nucleus (PMN). Previous studies have demonstrated that androgens lower the frequency of PMN discharge and concomitantly lower the best frequencies (BFs) of electroreceptors. In order to determine if the PMN serves as an internal reference for the hormone-mediated retuning of electroreceptors, the PMN was lesioned and the change in mean BF was measured for dihydrotestosterone (DHT)implanted or control animals. DHT-implanted fish showed the characteristic lowering of mean electroreceptor BF by $\sim 25 \%$, a significant change compared with controls ( $p<$ 0.01 , Mann-Whitney). This result indicates that the PMN is not necessary for the hormone-mediated shift of electroreceptor tuning.
\end{abstract}

In a related study, the contribution of the PMN to the genesis of tuning in regenerating electroreceptors was examined by removing a patch of cheek skin from PMN-lesioned fish. Regenerating electroreceptors became sharply tuned to the previous EOD frequency by 6 weeks in the same fashion as regenerating receptors in intact fish. In addition, intact receptors from PMN-lesioned fish remained tuned for up to $160 \mathrm{~d}$. Together, these results demonstrate that the pacemaker nucleus is unnecessary for the maintenance, development, or hormone-mediated shift of receptor tuning.

The weakly electric gymnotiform fish Sternopygus macrurus produces and detects a periodic electric field; this field is generated by an electric organ in the posterior trunk and tail and is detected by electroreceptors in the epidermis (for electroreception review, see Bullock and Heiligenberg, 1986). The electric organ discharge (EOD) of this species appears quasi-sinusoidal, and each fish discharges at its own individual frequency (Hopkins, 1976; Meyer and Zakon, 1982). The frequency of electric organ firing is determined by a medullary command, or pacemaker, nucleus (Bennett et al., 1967; Dye and Meyer, 1986). The pacemaker nucleus (PMN) is composed of pacemaker and relay cells; pacemaker cells are autorhythmic, electrotonically coupled cells that drive the discharge frequency of the electric organ via the relay cells, which synapse upon spinal motoneu-

Received June 1, 1988; revised Sept. 2, 1988; accepted Sept. 7, 1988

Grateful thanks to A. Mills and Drs. G. Pollak, D. Sanchez, W. Thompson, and W. Wilczynski for helpful comments on the manuscript. Thanks also to W. Wilczynski for help with histology, A. Ruggles and E. Guzman for animal maintenance, and J. Young and D. Speer for their artwork. This research was supported by NSF Grant BNS 8606744 .

Correspondence should be addressed to Michael B. Ferrari at the above address. Copyright (C) 1989 Society for Neuroscience $0270-6474 / 89 / 041354-04 \$ 02.00 / 0$ rons (Ellis and Szabo, 1980; Elekes and Szabo, 1981). These motoneurons, in turn, innervate the electrocytes of the electric organ. In this electromotor pathway, one PMN action potential results in a synchronized discharge of the electric organ.

The EOD is used for electrolocation, the evaluation of surrounding objects by their effect on EOD geometry (Lissmann and Machin, 1958), and for social communication, based on individual EOD frequencies and EOD modulations (Hopkins, 1972, 1974, 1981; Hagedorn and Heiligenberg, 1985). Electrolocation ability is maximized by the close match between the EOD frequency and the frequency tuning of a class of electroreceptors called tuberous electroreceptors (Hopkins, 1976; Viancour, 1979). The tuberous electroreceptors, as measured from their afferents, have sharp tuning curves, and the receptors of each fish are best tuned to its individual EOD frequency (Bastian, 1976, 1977; Hopkins, 1976; Zakon and Meyer, 1983).

Many species of weakly electric fish have a sexually dimorphic EOD at maturity (Meyer and Zakon, 1982; Bass and Hopkins, 1983, 1985; Hagedorn and Carr, 1985). Sternopygus exhibits a sexual dimorphism within its species EOD frequency range of 50-200 Hz: juveniles discharge around $100 \mathrm{~Hz}$, while mature males discharge at the lower frequencies $(50-100)$ and mature females discharge at the higher frequencies (100-200) (Hopkins, 1972). This sex difference in the electrosensory system is due to circulating gonadal steroids (Meyer and Zakon, 1982; Keller et al., 1986; Zakon et al., 1987). Previous studies have demonstrated that administration of the androgen $5 \alpha$-dihydrotestosterone (DHT) lowers the firing frequency of the PMN, and, therefore, the electric organ. DHT also lowers the frequency tuning of electroreceptors such that they remain matched to the lowered EOD frequency to preserve electrolocation ability (Meyer, 1983, 1984; Meyer et al., 1984). This hormone-dependent plasticity raises the question of how receptor tuning shifts to maintain the tight corrclation with PMN, and hence EOD, frequency (Meyer and Zakon, 1982; Zakon, 1987). Does the hormone directly affect electroreceptor tuning with subsequent secondary changes in PMN firing, does the hormone directly affect the PMN such that the lower EOD frequency indirectly retunes the receptors, or does the hormone act on the target tissues independently but in concert such that their electrical properties remain matched?

For Sternopygus, recent experiments have demonstrated that the EOD itself is unnecessary for the hormone-mediated shift in electroreceptor tuning (Keller et al., 1986). In these experiments, spinal transections silenced the EOD, and subsequent treatment with DHT resulted in lower best frequencies (BFs) of the tuberous electroreceptor population. Although it appears that the hormone directly affects electroreceptor tuning, the possibility remains that the lowered PMN firing frequency may in 
some way entrain the electroreceptors, even though the only PMN output is to the spinal motoneurons, and electroreceptors receive no efferent innervation (Szabo, 1965, 1974; Wachtel and Szamier, 1966; Szamier and Wachtel, 1970).

In a related study on tuning plasticity, tuberous electroreceptors were induced to regenerate in electrically silenced and intact animals (Zakon, 1986). After skin removal, new receptors form and gradually become tuned to the ongoing EOD frequency or, in the case of spinally transected animals, the previous EOD frequency. Again, in these experiments, the PMN may have served as a reference, or calibration signal, for the developing receptors. Therefore, in the current study, in order to determine the contribution of the PMN to hormone-mediated tuning plasticity or tuning development, we examined electroreceptor tuning in fish administered DHT and fish with regenerating skin in which the pacemaker nucleus was lesioned.

\section{Materials and Methods}

Experimental subjects. Adult $S$. macrurus $(20-30 \mathrm{~cm}$, collected from the Apure drainage basin, Venezuela) were housed individually in aerated 10 gallon aquaria, maintained on a $12 \mathrm{hr}$ light/12 hr dark cycle, and fed a daily diet of frozen bloodworms or live earthworms. Fish of both sexes were used since they show no difference in their responses to the treatments used in this study. Water temperature was maintained at $\sim 25^{\circ} \mathrm{C}$. In some cases, freshwater was replaced with 50 or $100 \%$ isotonic saline for a few days to prevent the possible loss of animals after lesion surgery. Fish were monitored to determine the stability of the EOD frequency, and only fish that had stable EOD frequencies for at least 2 weeks were used. For each fish, the baseline recording, pacemaker lesion, and experimental treatments described below were all performed within $24 \mathrm{hr}$.

\section{Experiment I: Hormone treatment}

Afferent recording. Recordings from the tuberous electroreceptor afferent population were made as previously described (Zakon and Mcycr, 1983; Zakon, 1986). Briefly, fish were curarized (0.1-0.3 mg, tubocurarine, Sigma), held just below the surface in a recording tank with a foamlined holder, and respirated with aerated water. Recording tank temperature was maintained at $25 \pm 0.2^{\circ} \mathrm{C}$. A dorsolateral portion of the head was raised from the water in order to expose the posterior branch of the anterior lateral line nerve (pALLN). After application of a topical anesthetic ( $5 \%$ procaine, Sigma), the posterior branch, which innervates receptors on the body, was exposed and glass microelectrodes $(3 \mathrm{M} \mathrm{KCl}$, $20-50 \mathrm{M} \Omega$ ) were used to record the single-unit responses of $20-25$ tuberous units. An external AC electric field approximating the EOD was generated with a function generator and passed through an attenuator so that the frequency and intensity could be varied. The best frequency (BF) of a tuberous unit was then taken as the lowest intensity and frequency at which the unit was still phase-locked 1:1 to the stimulus field. The BFs of all units were then averaged to give an indication of the animal's mean best frequency $(\bar{x} \mathrm{BF})$ of electroreceptor tuning. This procedure was used to determine baseline $x \mathrm{BF}$ in subsequent recording sessions. In addition, $Q_{10 \mathrm{~dB}}$ values were calculated for each unit in order to quantify the unit's sharpness of tuning. $Q_{10 \mathrm{~dB}}$ is determined by dividing a unit's $B F$ by the bandwidth of its tuning curve at $10 \mathrm{~dB}$ above threshold.

Pacemaker lesions. Following the baseline recordings, fish were held vertically, the top of the head was swabbed, and subcutaneously injected with $5 \%$ procaine. A dorsal incision was made in the skin above the hindbrain, the muscle and cartilage overying the cerebellum were cut, and the dura matter was removed. A glass microelectrode $(\sim 20-30 \mu \mathrm{m}$. tip, $3 \mathrm{M} \mathrm{KCl}$ ) was then lowered into the brain to record extracellular activity. Successive penetrations were made to find the field potentials of the PMN. Small but distinct $(\sim 50 \mu \mathrm{v})$ pacemaker potentials can be recorded in the vicinity of the PMN, presumably by volume conduction and from descending axons. Once the electrode enters the PMN, the potential rapidly grows to an amplitude of a few hundred microvolts to $1 \mathrm{mV}$, and it may reverse in polarity lower in the nucleus (described by Bennett et al., 1967). Further advancing of the electrode by only a few tens of microns reduces the potential amplitude and indicates that the electrode is moving out of the nucleus. W

'MN localized the microelectrode was raised and changed for 0 ining $5 \% \mathrm{CoCl}_{2}$ in $3 \mathrm{M} \mathrm{NaCl}$ (treatment of the PMN with cadmium in a slice preparation irreversibly blocks PMN activity; Maler et al., 1984). This electrode $(\sim 20 \mu \mathrm{m}$ tip) was attached to a microliter syringe via polyethylene tubing and the whole system was filled with $3 \mathrm{~m} \mathrm{NaCl}$. Pacemaker activity was recorded via a Grass P-15 AC-coupled amplifier attached to the syringe needle. This electrode was then advanced into the PMN and held in the region of the highest amplitude pacemaker potentials. A small pressure injection $(<1 \mu \mathrm{l})$ was then made with the syringe. This often silenced the PMN completely, but in some cases activity recovered and subsequent injections were necessary. The electrode was left in place for 30 min to confirm that pacemaker activity did not resume. The electrode was withdrawn and the incision was closed with histoacryl glue or sutured.

Confirmation of the PMN lesion was made.by recording externally from the tail to determine if an EOD was present after recovery from the curare and before subsequent recording sessions. Previous histological results show that a lesion that silences the EOD kills virtually all of the pacemaker cells; if some are left, the EOD will return $(\mathrm{H}$. Zakon, unpublished observations). Thus, we knew that complete lesions were caused by the lack of an EOD. Nevertheless, some animals were killed at various postlesion times for histological analysis of the PMN in this study as well. Fish were anesthetizcd with MS-222 (Sigma) and perfused through the heart with Hickman's Ringer followed by $10 \%$ formalin in Ringer's. Whole brains, fixed in $10 \%$ formalin in Ringer's, were paraffinembedded, sectioned $(10 \mu \mathrm{m})$, and stained with cresyl violet.

Hormone treatment. Following baseline recording and the PMN lesion, fish were implanted with DHT-filled or empty silastic capsules (Keller et al., 1986). Capsule implantation was made in the peritoneal cavity and the incision sealed with histoacryl glue. These capsules release DHT in concentrations of a few to $10 \mathrm{ng} / \mathrm{ml}$ of plasma, approximating the levels of endogenous androgens in wild-caught or gonadotropinprimed animals ( $\mathrm{P}$. Thomas and $\mathrm{H}$. Zakon, unpublished observations; Zakon et al., 1987). These implantations also result in continuous release of the hormone and may cause less stress for the animal than daily injections. Recording of the change in $\bar{x} \mathrm{BF}$ was made 2 weeks after implantation as described above.

\section{Experiment II: Regeneration}

In order to study regenerating electroreceptors in the absence of a functioning PMN, the cheek epidermis was removed to induce the formation of new electroreceptors. In this related study, the afferent recording and pacemaker lesion procedures were the same as previously described with the exception that afferent recording was made from the anterior branch of the ALLN. Specifically, the infraorbital branch of the aALLN was used as this branch innervates electreceptors anterior to the operculum and ventral to the eye, i.e., the cheek region. This area was chosen for skin removal because of its high density of electroreceptors and since previous regeneration work focused on this region (Zakon, 1986).

Skin removal. Fish were anesthetized (MS-222) and a patch of cheek skin removed. Patch size varied but was generally on the order of $0.5-$ $1 \mathrm{~cm}^{2}$. Care was taken to remove only the skin and avoid damage of the underlying muscles and vasculature.

Unit location. In fish with regenerating cheek skin, determination of the unit's location on the skin was necessary to define it as an intact or regenerating receptor unit. In this case, after recording the unit's BF, the wide-field stimulus was switched off and a small dipole electrode (search field $\sim 1 \mathrm{~mm}^{2}$ ) was moved around the face to stimulate the unit focally (Zakon, 1986). The unit was then scored as intact or regenerating based on its location within or outside of the visible wound margin. The measurements of $\bar{x} \mathrm{BF}$ and determination of unit location were made 6 weeks after skin removal, since a previous study had demonstrated receptors were retuned to the EOD frequency by 6 weeks.

\section{Results}

\section{Pacemaker lesions}

The PMN is an unpaired, midline nucleus located in the anterior portion of the medulla, ventral to the 4 th ventricle (Fig. 1C). It is composed of 2 neuronal cell types, pacemaker cells and relay cells, previously described as small and large cells, respectively (Elekes and Szabo, 1981). The pacemaker cells are found in the 

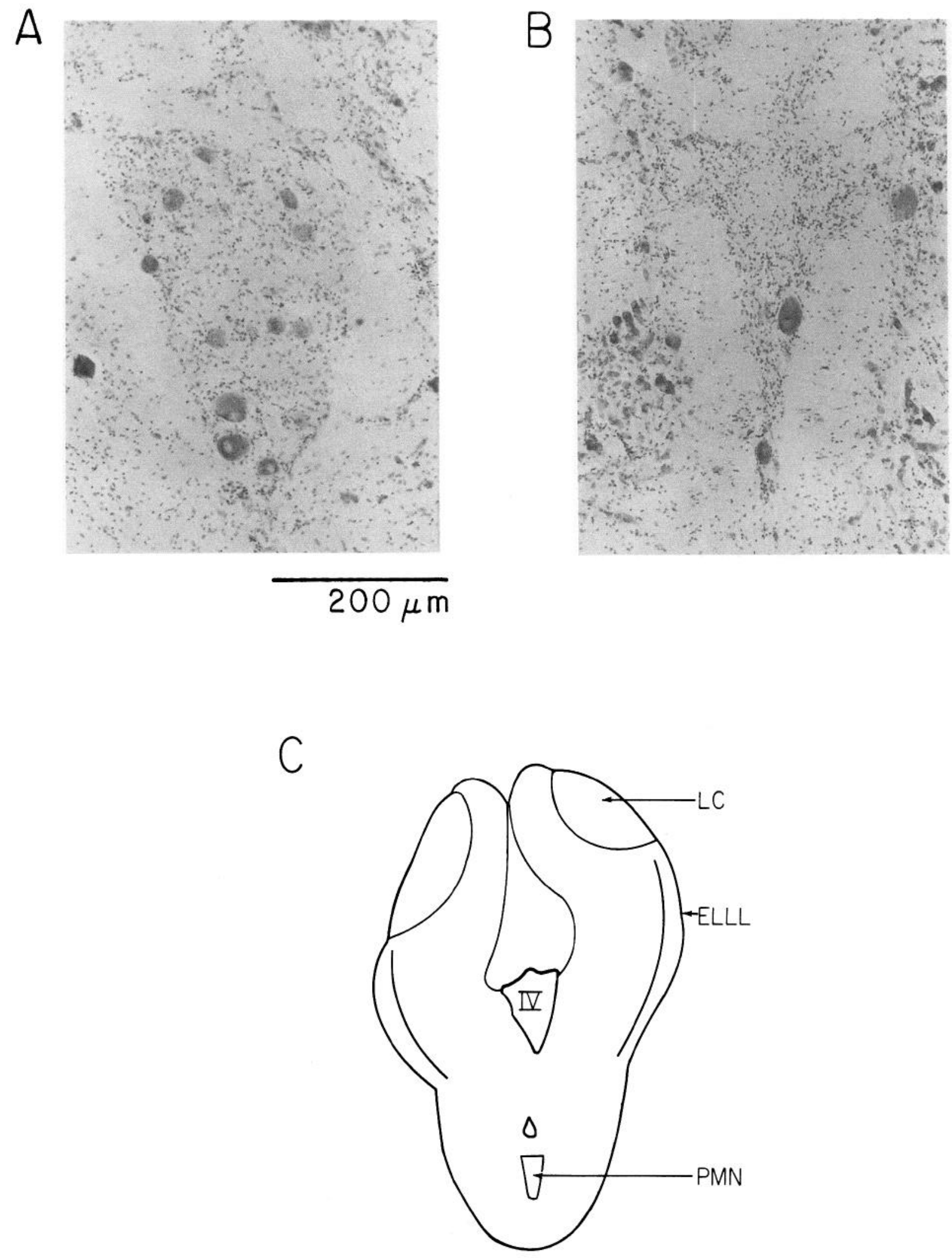

Figure 1. Transverse sections of the medullary pacemaker nucleus. $A$, Thick section $(10 \mu \mathrm{m})$ stained with cresyl violet showing characteristic wedge-shape of this unpaired nucleus. This nucleus is comprised of 2 cell types, relay (large somas and ventral) and pacemaker (small somas and dorsal) cells. The ratio of pacemaker to relay cells in normal fish is $2: 1$. $B$, Similar section from a nucleus several weeks after pressure injection of cobalt chloride. The lesion site shows a loss of pacemaker cells and some gliosis. Relay cells, however, appear intact and are found in normal numbers. Note the shrunken size of the nucleus, which was seen throughout its rostrocaudal extent. Scale bar, $200 \mu \mathrm{m}$. $C$, Camera lucida drawing of the hindbrain at the level of the PMN. $E L L L$, Electrosensory lateral line lobe; $L C$, lobus caudalis; $P M N$, pacemaker nucleus; $I V$, fourth ventricle. 
A

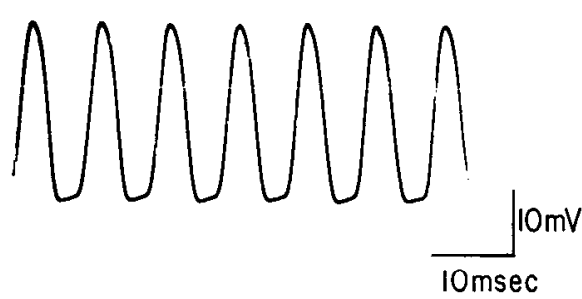

B

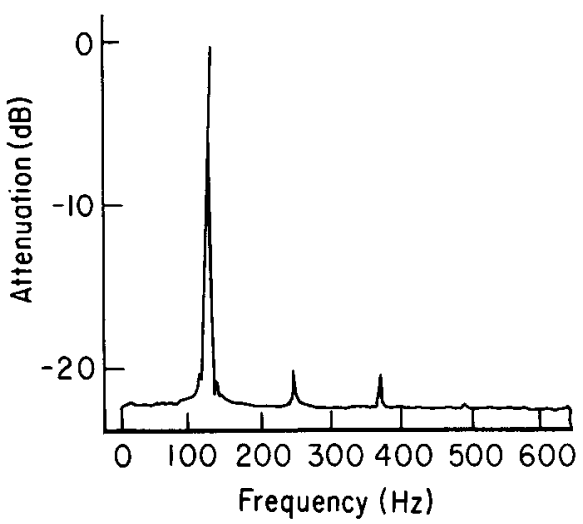

C



D



Figure 2. Electric organ activity in normal and lesioned animals. $A$, Normal EOD recorded externally from tail showing highly regular quasi-sinusoidal discharge. $B$, Fourier analysis of the normal EOD. The peak power is centered at the fundamental with some energy at the next 2 harmonics. $C$, Lowvoltage activity recorded from the tail of a lesioned fish. Note the low-frequency component of an otherwise irregular discharge and lower amplitude compared with $A$. $D$, Fourier analysis of activity in $C$. Peak power is centered at about $10 \mathrm{~Hz}$ in lesioned animals in an otherwise broad and irregular spectrum. In both $B$ and $D$ the amplitude is given relative to the peak frequency. dorsal portion of the nucleus and have a more granular staining pattern compared with the relay cells, which are located ventrally and stain darkly (Fig. $1, A, B$ ). The ratio of pacemaker to relay cells in normal animals is 2:1 (Ellis and Szabo, 1980); for example, counts of cell nucleoli from a normal PMN yielded 174 pacemaker cells to 81 relay cells. However, inspection of 2 lesioned PMN reveal few, if any, pacemaker cells (Fig. $1 B$; representative section). Relay cells, however, appear to have survived the lesion as they occur in normal numbers throughout these nuclei. Lesioned nuclei show some gliosis and a shrinkage in cross-sectional area throughout the extent of the nucleus, but cell groups near the PMN appeared normal. In fact, larger injections that resulted in leakage into the medulla typically resulted in an inability to move the gills and subsequent death.

Injections of cobalt chloride usually resulted in an immediate cessation of PMN activity, but on most occasions activity gradually resumed within 10-20 min and additional small injections were necessary. As the mechanism of cobalt toxicity is unknown, we do not know if this was due to a particular resiliency of the pacemaker cells, inadequate volume injections, or a slow time course of action of the cobalt.

External recordings from the tails of lesioned fish indicate that the cobalt causes a functional ablation of the PMN and a silencing of the EOD. Figure 2, $A, B$, shows a normal EOD and its power spectrum. The normal discharge is highly regular and quasi-sinusoidal with peak power at the fundamental frequency of the EOD. However, in all lesioned fish, only a characteristic low-voltage activity could be monitored, present from the moment of curare recovery onward (Fig. $2 C$ ). The peak power of this activity was centered around $10 \mathrm{~Hz}$ in all fish (Fig. $2 D$ ) and approximately $2 \mathrm{mV} / \mathrm{cm}$ at the tip of the tail as opposed to the $20 \mathrm{~m} V / \mathrm{cm}$ seen in normal fish. We believe this activity had no effect on the tuberous electroreceptors for the following reasons: (1) Even if the receptors could be driven by this residual activity, most of the energy is at $10 \mathrm{~Hz}$, a frequency to which tuberous electroreceptors are insensitive; (2) the activity riding on the 10 $\mathrm{Hz}$ component is too asynchronous to temporally modulate the receptors in any meaningful way; and (3) both DHT-treated and control animals exhibited this activity, but tuberous electroreceptor tuning was altered only for the hormone-treated fish (see Fig. 3).

In order to determine the site of origin of the $10 \mathrm{~Hz}$ activity, one lesioned animal was given a midspinal transection. It showed a subsequent loss of the $10 \mathrm{~Hz}$ component but continued asynchronous activity typical of spinally transected animals. This asynchronous activity disappeared after curarization. In all other respects the lesioned animals showed normal behavior.

\section{Hormone treatment}

The BFs of normal tuberous electroreceptor units, when averaged, show a close match to the EOD frequency. In general, the most sensitive units are tuned slightly higher than the EOD, while the least sensitive units are tuned somewhat lower, and the mean BF is often a few Hertz higher than the EOD. The exact relationship between $\bar{x} \mathrm{BF}$ and EOD frequency, however, also dcpends on the size of the fish (Sanchez, 1988). The tuning curves from lesioned animals show similar characteristics. There were no significant changes in the range of sensitivities $(-80$ to $-13 \mathrm{~dB} ;-20 \mathrm{~dB}=20 \mathrm{mV} / \mathrm{cm}$ ) or the sharpness of tuning (difference in $\bar{x} Q_{10 \mathrm{~dB}}$ between groups, $p<0.143$, Mann-Whitney) for individuals after the PMN lesion. The PMN lesion, therefore, seems to have had no effect on tuning curve parameters.

Recordings from tuberous afferents 2 weeks after implantation of DHT capsules show that the $\bar{x} \mathrm{BF}$ tuning of individual 




Figure 3. Bar graph of the percentage change in $\bar{x}$ BF for DHT versus control implants. The mean change for experimentals is $-25.4 \%(n=$ 5 ), while controls averaged $-7.1 \%(n=4)$. The difference between groups is significant ( $p<0.01$, Mann-Whitney). Numbers below the bars represent prelesion EOD frequency; letters simply denote fish designation. Note fish RX, which first received a control implant, with little change in tuning, followed by a DHT-induced tuning shift of $-17.8 \%$.

fish is lowered $16.9-35.5 \%$ relative to the prelesion/implant $\bar{x}$ BF. The mean percentage change for DHT implanted animals was $-25.4 \%(n=5)$. Controls showed a mean change of $-7.1 \%$ $(n=4)$. These two groups are statistically different at $p<0.01$ (Mann-Whitney), as demonstrated in Figure 3. Note that fish RX first received an empty control implant and then a DHT implant, thus serving as its own control. For this fish, a control drop of $1.9 \%$ was followed by a DHT-induced tuning shift of $-17.8 \%$. In addition, 2 separate fish, $B$ and $X$, had the same starting EOD frequency (and $\bar{x} \mathrm{BF}$ ) and the control showed a change of $-3.5 \%$, while the experimental dropped $-23.2 \%$. This hormone-induced shift in $\bar{x} \mathrm{BF}$ is not statistically distinguishable from the responses seen in intact, DHT-treated animals (mean $=-23.4 \%, n=5$; Keller et al., 1986).



Figure 4. Mean BFs of intact (filled circles) and regenerated (open circles) tuberous electroreceptors versus EOD frequency $(n=4)$. The $45^{\circ}$ line indicates a perfect match between receptor BF and EOD frequency. Error bars are SD.

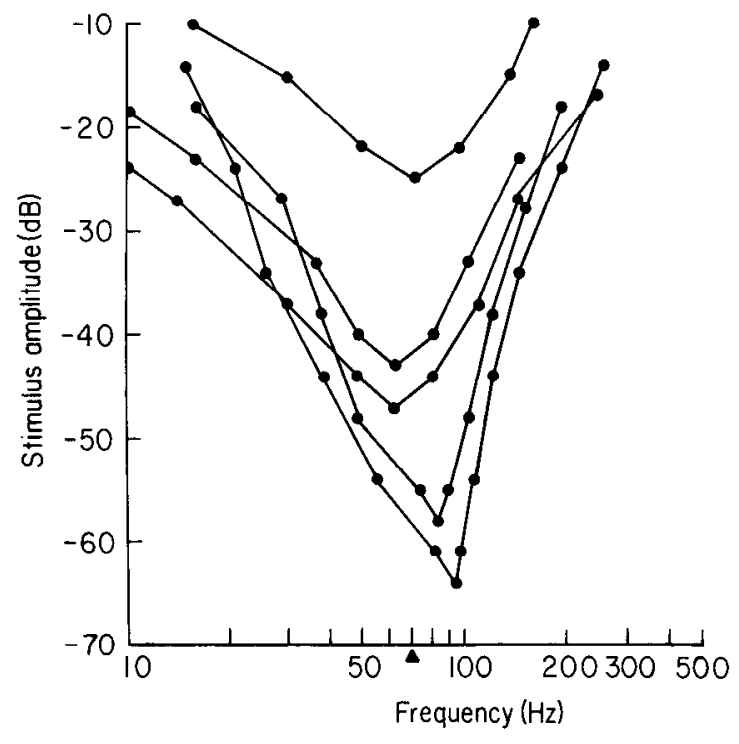

Figure 5. Representative tuning curves recorded $160 \mathrm{~d}$ postlesion from intact electroreceptors. The prelesion EOD (triangle) was $70 \mathrm{~Hz}$. These curves do not differ from those recorded in normal fish. The higher frequency selectivity in sensitive units versus the less-sensitive units is typical. A total recording of 21 units gave an average BF of $78.1 \pm 19.7$ $\mathrm{Hz}$.

\section{Regeneration}

Cheek skin was removed from 4 fish following PMN lesion, and the tuning properties of regenerated and intact receptors were studied 2 months after skin removal. The intact receptors (filled circles, Fig. 4) were still tuned to the fish's prelesion EOD frequency and possessed tuning curves with normal $Q_{10 \mathrm{~dB}}$ values. Regenerated receptors (open circles, Fig. 4) appeared similar to those recorded in a previous study using fish with an intact electromotor system and fish with a spinal transection that blocked the electric field but left the PMN unaffected (Zakon, 1986). In 3 of 4 cases, there was no significant difference between the mean BFs of the intact and regenerated receptors ( $t$ test). In the fourth case, the mean BF of the regenerated receptors was significantly lower than the BF of intact receptors $(p<0.05$, 1 -tailed $t$ test) and, therefore, lower than the previous EOD frequency. This is not surprising, as skin regeneration proceeds at various rates and it is not unusual for some regenerating receptors to be tuned lower than intact ones even 2 months after skin removal. In 2 of the 4 fish, the mean $Q_{10 \mathrm{~dB}}$ of regenerated units was significantly lower than those of intact receptors. This is not unexpected, however, as it is also true of regenerated units in intact fish (Zakon, 1986).

\section{Maintenance of tuning}

In order to examine if the PMN was necessary for the maintenance of electroreceptor tuning, $\bar{x}$ BFs were taken for some intact receptors up to 2 months postlesion. In no case did the mean best frequency or sharpness of tuning change by a significant amount, and in one animal the original tuning was unchanged at 5 months postlesion. Figure 5 plots representative tuning curves from this fish against the original prelesion FOD frequency of $70 \mathrm{~Hz}$. As is the case for intact fish, the most sensitive units are tuned slightly higher than the EOD, while the least sensitive units are tuned somewhat lower. As a population, however, the $\bar{x} \mathrm{BF}$ was $75.5 \mathrm{~Hz} \pm 16.9$ at $100 \mathrm{~d}$ and 
$78.1 \mathrm{~Hz}+19.7$ at $160 \mathrm{~d}$. The tuning curves in Figure 5 are from the $160 \mathrm{~d}$ recording.

\section{Discussion}

\section{Ablation of the PMN}

The key findings of this study are that functional ablation of the PMN does not alter the genesis, maintenance, or hormoneinduced shift of electroreceptor tuning. Our results, therefore, are contingent on the demonstration of a functional pacemaker lesion. The anatomical evidence is supportive, in that no pacemaker cells were noted in histological sections of lesioned nuclei. The pacemaker cells are an autorhythmic population having strong axosomatic and axodendritic electrical synapses upon one another and weaker electrical synapses with relay cells (Bennett et al., 1967). The loss of pacemaker cells may be due to a particular susceptibility to the cobalt, which may have becn enhanced by their strong electrical coupling. This selective loss could have been enhanced if the cobalt entered cells damaged by the penetrating microelectrode and then, via the electrical junctions, passed to the remaining cells. In this regard it is interesting to note the apparent survival of the relay cells. The few relay cells damaged, if any, may not have resulted in a loss of the relay cell population, as they are not strongly coupled in this species (Bennett et al., 1967). It is also possible that the pacemaker cells, but not the relay cells, are permeable to the cobalt. Future investigations using intracellular injections of cobalt in vivo or in slice preparations could distinguish between these possibilities.

The external recordings from the tails of lesioned fish provide evidence for the loss of pacemaker function, correlated with the anatomical evidence of the absence of these cells. The residual low-voltage asynchronous activity did not affect electroreceptor tuning as evidenced by the $\bar{x}$ BF change in DHT-treated versus control animals and the development of normal tuning in regenerating receptors. All lesioned fish exhibited this activity, but only androgen-treated fish showed tuning shifts, and intact and regenerating receptors remained, or became tuned to, the prelesion EOD frequency.

The $10 \mathrm{IIz}$ component of this low-voltage activity appears to have arisen supraspinally, as the one lesioned animal given a high spinal transection showed a loss of this low-frequency component while the asynchronous activity remained. The relay cells seem a logical candidate for the origin of this $10 \mathrm{~Hz}$ activity since the histology reveals their presence in normal numbers. There have been, however, no reports of autorhythmic behavior in these cells. Alternatively, the pre-PMN, which provides the sole input to the PMN in the related wave gymnotids Eigenmannia and Apteronotus (Heiligenberg et al., 1981, and unpublished observations; Dye and Heiligenberg, 1987), is capable of modulating the pacemaker discharge in these species. Bennett et al. (1967) reported the presence of chemical synaptic contacts on pacemaker and relay cells in Sternopygus; presumably these are also inputs from the prepacemaker, but this has yet to be demonstrated. It is therefore possible the intact inputs from this nucleus to the relay cells cause the obscrved $10 \mathrm{~Hz}$ activity after ablation of the pacemaker cells. This alternative is less likely, as the unit activity in the prepacemaker shows no $10 \mathrm{~Hz}$ rhythmicity (Rose et al., 1988). The steady asynchronous activity, however, clearly originated at the electric organ since it could be blocked by curare. This activity is likely due to activation of electrocytes by randomly firing motoneurons.

\section{Hormone-mediated electroreceptor tuning}

How do the sharply tuned electroreceptors of Sternopygus remain calibrated with the EOD during EOD frequency shifts? Investigation of the possible calibration mechanism of hormone-mediated shifts in electroreceptor tuning has focused on which of the electrically active tissues known to be affected by androgen administration could serve to "retune" or calibrate the electroreceptors. Previous studies (Meyer et al., 1984; Keller et al., 1986) have shown that the ongoing EOD is not necessary for the observed shifts in tuning. In these studies it was also demonstrated that the androgen does not merely work as a permissive agent since fish with spinal transections were placed into artificial fields of high frequency and electroreceptor tuning still shifted downward. In addition, if the PMN firing frequency is decreased by focal implants of DHT directly into the PMN, the electroreceptors show little or no shift in tuning (N. Markovitz, M. Fcrrari, and H. Zakon, unpublished obscrvations). Our results further suggest that neither the PMN nor the ongoing EOD are necessary for the observed androgen-induced shifts in electroreceptor tuning. This result provides strong evidence for the direct action of the hormone on electroreceptors.

For Brienomyrus brachyistius triphasic, a weakly electric African mormyrid with a pulse-type EOD, it appears that the EOD is necessary for the hormone-mediated shifts in receptor tuning (Bass and Hopkins, 1984). In this species, in which the peak power of the EOD pulse is at $1.2 \mathrm{KHz}$ for females and $0.3 \mathrm{KHz}$ for males, androgen administration to females causes downward shifts in EOD peak power and electroreceptor tuning (Bass and Hopkins, 1983). However, when the EOD is silenced by spinal transection, androgens do not cause tuning shifts in gonadectomized animals (Bass and Hopkins, 1984). As proposed by Bass and Hopkins (1984), the androgen may allow the electroreceptors to become entraincd only to an ongoing EOD. It rcmains difficult to envision the biophysical bases of how an ongoing EOD could alter electroreceptor tuning, but the highfrequency tuning of mormyrid receptors (in Pollimyrus isidori as high as $18 \mathrm{kHz}$ : Hopkins, 1981) may be due to quite different mechanisms than those proposed for wave gymnotoids (Zakon, 1986), and the mechanisms of tuning plasticity may therefore differ.

For Sternopygus, it now appears that induced frequency shifts in the electrosensory system are due to a neuroendocrinological coordination of independent androgen-sensitive sites (Zakon, 1987; Zakon et al., 1987). Of even broader interest is the fact that the 3 androgen-receptive components of this system have different developmental origins: the pacemaker presumably is from neuroectoderm, the electric organ is myogenically derived, and electroreceptors arise presumably from the dorsolateral placode, as do related hair cell receptors of the octavo-lateralis system. If the androgen, or its metabolites, acts directly on each tissue in this system, how does each tissue recognize the proper end point? It is perplexing to imagine that steroid hormones circulating at a few nanograms per milliliter of plasma could effectively signal the correct magnitude of changes in electrical properties for each tissue type.

\section{Regeneration and maintenance of electroreceptor tuning}

Electroreceptors regenerate in the skin of electrically silenced (Zakon, 1986) and PMN-lesioned fish. This indicates that neither the EOD nor the PMN is necessary for the induction of new receptors nor their proper physiological development. More 
importantly, receptors regenerate and develop tuning characteristics in PMN-lesioned fish that are indistinguishable from intact receptors. This developmental tuning plasticity further supports the idea that receptor tuning is independent of central or motor control. The regeneration results presented here again raise the interesting question of how receptors recognize their proper "end point?"

These regeneration results do not distinguish between a possible developmental genetic set point, which the receptor gradually reaches and at which it stabilizes, or the influence of circulating sex steroids or other factors during electroreceptor development. This question could be investigated by using allografts from high- to low-frequency fish with and without gonadectomies to investigate the possible contribution of, and receptor competency to respond to, varying levels of endogenous steroids.

\section{Concluding remarks on peripheral sensory plasticity}

The first suggestions that hormones might affect peripheral sensory components were made by Nissen (1929) and Beach (1948). Examples of plastic sensory components that respond to endogenous or exogenous steroid hormones exist, but are limited. As previously mentioned, weakly electric mormyrids also show lability in electroreceptor tuning after androgen administration. In the fire-bellied toad, Bombina, gonadotropin induces the formation of lateral line hair cells after metamorphosis, presumably by release of endogenous sex steroids (U. Will and B. Fritzsch, personal communication). These hair cells also appear to arise during the breeding season from latent receptor organs. Kow and Pfaff (1973) have reported that tactile receptive fields of estrogen-primed female rats increase in sizc and show a trend toward increased sensitivity. There is, as yet, no strong evidence for tuning plasticity for any vertebrate auditory system. Although there are reports of sex differences in the tuning of auditory receptors in amphibians (Narins and Capranica, 1976; Wilczysnki et al., 1983), no study has investigated the role of steroids in its development. It is likely, however, that this difference is not primarily due to steroids, but rather results from allometric growth changes within the auditory papillae (Wilczynski et al., 1984).

The electroreceptors of weakly electric fish represent an unusual case of peripheral sensory pliancy. This class of sensory receptors may change their electrical filtering properties in order to maximize their sensitivity to the stimulus available, the EOD. This is most likely achieved by changes in active ion conductances of the receptor membrane, and this will be the focus of future investigations.

\section{References}

Bass, A. H., and C. D. Hopkins (1983) Hormonal control of sexual differentiation: Changes in electric organ discharge waveform. Science 220: 971-974.

Bass, A. H., and C. D. Hopkins (1984) Shifts in frequency tuning of electroreceptors in androgen-treated mormyrid fish. J. Comp. Physiol. A 155: 713-724.

Bass, A. H., and C. D. Hopkins (1985) Hormonal control of sex differences in the electric organ discharge (EOD) of mormyrid fishes. J. Comp. Physiol. A 156: 587-604.

Bastian, J. (1976) Frequency response characteristics of electroreceptors in weakly electric fish (Gymnotoidei) with a pulse discharge. J. Comp. Physiol. 112: 165-180.

Bastian, J. (1977) Variations in the frequency response of electroreceptors dependent on receptor location in weakly electric fish (Gymnotoidei) with a pulse discharge. J. Comp. Physiol. 121: 53-64.
Beach, F. A. (1948) Hormones and Behavior, Hoeber, New York.

Bennett, M. V. L., G. D. Pappas, M. Gimenez, and Y. Nakajima (1967) Physiology and ultrastructure of electrotonic junctions. IV. Medullary electromotor nuclei in gymnotid fish. J. Neurophysiol. 30: 236-300.

Bullock, T. H., and W. Heiligenberg (1986) Electroreception, Wiley, New York.

Dye, J., and W. Heiligenberg (1987) Intracellular recording in the medullary pacemaker nucleus of the weakly electric fish, Apteronotus. J. Comp. Physiol. A 161: 187-200.

Dye, J. C., and J. H. Meyer (1986) Central control of the electric organ discharge in weakly electric fish. In Electroreception, T. H. Bullock and W. Heiligenberg, eds., pp. 71-102, Wiley, New York.

Elekes, K., and T. Szabo (1981) Comparative synaptology of the pacemaker nucleus in the brain of weakly electric fish (Gymnotidae). In Sensory Physiology of Aquatic Iower Vertebrates, T. Szabo and G. Czeh, eds., pp. 188-278, Pergamon, New York.

Ellis, D. B., and T. Szabo (1980) HRP identification of different cell types in the command (pacemaker) nucleus of several gymnotid species. Neuroscience 5: 1917-1929.

Hagedorn, M., and C. E. Carr (1985) Single electrocytes produce a sexually dimorphic signal in the South American electric fish, $\mathrm{Hy}$ popomus occidentalis. J. Comp. Physiol. A 156:511-523.

Hagedorn, M., and W. Heiligenberg (1985) Court and spark: Electric signals in the courtship and mating of gymnotid tish. Anim. Behav. 33: 254-265.

Heiligenberg, W., T. Finger, J. Matsubara, and C. Carr (1981) Input to the medullary pacemaker nucleus in the weakly electric fish, $E i$ genmannia (Sternopygidae, Gymnotiformes). Brain Res. 211: 418423 .

Hopkins, C. D. (1972) Sex differences in signalling in an electric fish. Science 176: 1035-1037.

Hopkins, C. D. (1974) Electric communication in the reproductive behavior of Sternopygus macrurus. Z. Tierpsychol. 35: 518-535.

Hopkins, C. D. (1976) Stimulus filtering and electroreception: Tuberous electroreceptors in three species of gymnotid fish. J. Comp. Physiol. 111: 171-207.

Hopkins, C. D. (1981) On the diversity of electric signals in a community of mormyrid electric fish in West Africa. Am. Zool. 21:211222.

Keller, C. H., H. H. Zakon, and D. Y. Sanchez (1986) Evidence for a direct effect of androgens upon electroreceptor tuning. J. Comp. Physiol. A 158: 301-310.

Kow, I. M., and D. W. Pfaff (1973) Effects of estrogen treatment on the size of receptive field and response threshold of pudendal nerve in the female rat. Neuroendocrinology 13: 299-313.

Lissmann, H. W., and K. E. Machin (1958) The mechanism of object location in Gymnarchus niloticus and similar fish. J. Exp. Biol. 35: $451-486$.

Maler, L., M. Boland, J. Patrick, and W. Ellis (1984) Localization of zinc in the pacemaker nucleus of high frequency gymnotid fish. In The Neurobiology of Zinc, Part A: Physiochemistry, Anatomy, and Techniques, C. Frederickson, G. A. Howell, and E. S. Kasarskis, eds., pp. 199-212, Liss, New York.

Meyer, J. H. (1983) Steroid influences upon the discharge frequencies of weakly electric fish. J. Comp. Physiol. A 153: 29-37.

Meyer, J. H. (1984) Steroid influences upon discharge frequencies of intact and isolated pacemakers of weakly electric fish. J. Comp. Physiol. A 154: 659-668.

Meyer, J. H., and H. H. Zakon (1982) Androgens alter the tuning of clectrorcceptors. Scicnce 217: 635-637.

Meyer, J. H., H. H. Zakon, and W. Heiligenberg (1984) Steroid influences upon the electrosensory system of weakly electric fish: Direct effects upon discharge frequencies with indirect effects upon electroreceptor tuning. J. Comp. Physiol. A 154: 625-631.

Narins, P., and R. Capranica (1976) Sexual differences in the auditory system of the tree frog Eleutherodactylus coqui. Science 192: 378380 .

Nissen, H. W. (1929) The effects of gonadectomy, vasotomy, and injections of placental and orchic extracts on the sex behavior of the white rat. Genet. Psychol. Monogr. 5: 451-547.

Rose, G. J., M. Kawasaki, and W. Heiligenberg (1988) "Recognition units" at the top of a neuronal hierarchy? J. Comp. Physiol. A 162: $759-772$.

Sanchez, D. Y. (1988) The Effects of Postembryonic Receptor Cell Addition on Response Properties of Afferents in the Electrosensory 
System of Sternopygus macrurus. Ph.D. dissertation, University of Texas, Austin.

Szabo, T. (1965) Sense organs of the lateral line system in some electric fish of the Gymnotidae, Mormyridae and Gymnarchidae. J. Morphol. 117: $229-250$

Szabo, T. (1974) Anatomy of the specialized lateral line organs of electroreception. In Handbook of Sensory Physiology, Vol. 3, Pt. 3, A. Fessard, ed., pp. 13-58, Springer-Verlag, New York.

Szamier, R. B., and A. W. Wachtel (1970) Special cutaneous receptor organs of fish. VI. Ampullary and tuberous organs of Hypopomus. J. Ultrastruct. Res. 30: 450-471.

Viancour, T. A. (1979) Flectroreceptors of a weakly electric fish. I. Characterization of tuberous receptor organ tuning. J. Comp. Physiol. 133: 317-325.

Wachtel, A. W., and R. B. Szamier (1966) Special cutaneous receptor organs of fish: The tuberous organs of Eigenmannia. J. Morphol. 119: 51-80.
Wilczynski, W., H. H. Zakon, and E. A. Brenowitz (1983) A sex difference in basilar papilla tuning in the Hyla crucifer auditory system and its behavioral significance. Soc. Neurosci. Abstr. 9: 531.

Wilczynski, W., H. H. Zakon, and E. A. Brenowitz (1984) Acoustic communication in spring peepers: Call characteristics and neurophysiological aspects. J. Comp. Physiol. A 155: 577-584.

Zakon, H. H. (1986) The emergence of tuning in newly generated tuberous electroreceptors. J. Neurosci. 6: 3297-3308.

Zakon, H. H. (1987) Hormone-mediated plasticity in the electrosensory system of weakly electric fish. Trends Neurosci. 10: 416-421.

Zakon, H. H., and J. H. Meyer (1983) Plasticity of electroreceptor tuning in the weakly electric fish, Sternopygus dariensis. J. Comp. Physiol. A 153: 477-487.

Zakon, H. H., H. Y. Yan, and P. Thomas (1987) Gonadotropininduced shifts in the electrosensory system of Sternopygus. Soc. Neurosci. Abstr. 13: 621. 